\title{
Social Network Structure as a Moderator of the Relationship between Psychological Capital and Job Satisfaction: Evidence from China
}

\author{
Fan Gu $(1)$ and Yuanyuan Xiao \\ Business School, China University of Political Science and Law, Beijing 100088, China \\ Correspondence should be addressed to Fan Gu; gufan@cupl.edu.cn
}

Received 10 June 2021; Accepted 8 October 2021; Published 2 November 2021

Academic Editor: Fei Xiong

Copyright (c) 2021 Fan Gu and Yuanyuan Xiao. This is an open access article distributed under the Creative Commons Attribution License, which permits unrestricted use, distribution, and reproduction in any medium, provided the original work is properly cited.

\begin{abstract}
Although networking is reported to be a job search strategy in the literature, research on the interaction between social networking and other personal resources and its effect on job satisfaction is scarce. In the perspective of social networks, the present study explored whether the social network structure, which consists of network size and tie strength, moderates the relationship between psychological capital and job satisfaction. By using a two-wave longitudinal design, we collected the quantitative data (survey of 344 undergraduate students who were about to graduate soon) from 19 universities in Beijing city, Shandong Province, and Jiangsu Province in Eastern China. Factor analysis and hierarchical regression analysis were adopted to analyze the data of the survey. We found that psychological capital has a positive impact on job seekers' job satisfaction. Furthermore, smaller networks and weaker ties in social networks both render the positive effect of psychological capital on job satisfaction even stronger.
\end{abstract}

\section{Introduction}

Social networks, an essential component of social capital, refer to interpersonal relationships, which are built, developed, and maintained through stable ties and frequent interactions [1]. The previous research had divided social networks mainly into two typical categories: formal and informal networks [2]. Although social networks are reported to be universally valid, it is still found that social networks in China have unique characteristics compared to their counterparts in Western countries. Social networks in East Asia are influenced by local culture [3] and become a dominant norm in Chinese society [4]. Thus, due to the remarkable intraregional differences, scholars even adopted guanxi to describe the informal social network in Chinese society. Contrary to social networks in Western countries, weak ties are found neither effective nor preferable in Eastern Asia, while strong ties are more accepted and powerful [5]. Hence, the yawning divergence between the characteristics of social networks in China and the West is obvious.
Whether in China or in the West, a large number of fresh graduates are confronted with difficulty in seeking employment in the last year of their student lives. Chinese national government pays great attention to this issue and publishes reports to announce the rate of unemployment, which partly represents the economic prosperity of a country, every year. From the last year to the present, the coronavirus (COVID-19) pandemic leads to an increase in the rate of unemployment all over the world. As a matter of fact, a large number of studies showed that unemployment is harmful to individuals' mental and physical health and decreases satisfaction with their lives [6]. Therefore, the research had concentrated on the exploration of the relationship between individuals' job search behaviors and employment quality, such as job-organization fit, job satisfaction, and turnover intention [7-9], in order to clarify what factors in the job search process could eventually increase the individuals' opportunities of obtaining job offers and then enhance their performance [10].

Job satisfaction is defined by Locke [11] as "a pleasurable or positive emotional state resulting from the appraisal of 
one's job or job experiences." Obviously, Locke's definition consists of two important individuals' reactions: affects and cognition. As such, when individuals evaluate their jobs, both thinking and feeling are involved in the whole process. It is widely discussed that the determinants of job satisfaction primarily consist of two types: job-specific characteristics, such as wages, labor market status, and observable attributes of the current job, and worker-specific characteristics, such as workers' education background, health, and worker's perceptions of the match between education and employment [12].

The literature regarding job search behaviors and process also paid great attention to job satisfaction, which refers to job hunters' satisfaction with the outcome of the job-seeking behaviors, i.e., the job they finally obtained [13]. Scholars found that both of the job seekers' internal factors, such as psychological capital and social capital and human capital, and external factors, such as labor market and national employment policy, can influence their job satisfaction. Among all these factors, it is reported that the subjective factors, which are considered as job seekers' internal motivation to promote them to make great endeavors in the jobhunting process, influence their attitudes and behaviors to a large extent [14]. It is reported that a large amount of job seekers in China always experiences a long job-hunting process, which lasts from the beginning of the autumn to the end of the spring [15]. Moreover, the difficulties for all job seekers in finding a satisfactory job had been increased, due to the huge supply of fresh graduates in the Chinese labor market in recent years [15]. Thus, to help job seekers enhance their employment opportunities, it is essential to pay attention to their behaviors in the Chinese context.

Networking is an important source for job seekers to gather information regarding employment opportunities. A popular book, which introduces the techniques of job hunting, also suggests that individuals could obtain useful information on job vacancies by contacting the important persons who can help in their social networks [16]. This echoes the research on recruitment, which claimed that knowing the job opportunities through one's social networks always has a positive impact on employees' behaviors $[17,18]$. However, the previous research on the role of networking in the job search process primarily focused on individual difference determinants of networking [19] and the impact of networking on employment quality and outcomes [20]. It is obvious that the literature ignores the moderation effect of social networks on the relationship between other important internal factors (e.g., psychological capital) in the job search process and the quality of employment (e.g., job satisfaction). Thus, this study examines the moderation effect of social networks on the relationship between psychological capital and job satisfaction by responding to the following question:

How do social networks moderate the impact of psychological capital on job satisfaction?

In fact, this study takes an interactionist approach by bringing together individual variables (psychological capital) and contextual variables, that is, social network structure, to predict job satisfaction in a single frame for the first time. To answer the question above, the dependent variable in this study is "job satisfaction," while the independent variable is "psychological capital." "Social network structure" involving network size and tie strength is examined as the moderator of the relationship between psychological capital and job satisfaction. The exploratory factor analysis is used to assess common method variance among variables while the hierarchical regression model is adopted to test the influence of psychological capital on job satisfaction and the moderative effect of network size and tie strength on the relationship between psychological capital and job satisfaction (Figure 1).

As both social networks and job seekers' behaviors have a uniqueness in Chinese society, this study extends previous relevant research by examining the moderation effect of social network structure on the relationship between psychological capital and job satisfaction in the Chinese context. Thus, we could better realize the important role of social networks in Chinese daily life. This is the main academic contribution of this study.

\section{Literature Review and Hypotheses}

2.1. Networking Behaviors in Job Search Process. Networking behaviors refer to 'individuals' attempts to develop and maintain relationships with others who have the potential to assist them in their work or career" [21]. Networking behaviors are widely studied in various contexts in the management research field, because both organizations or individuals adopt social networks as a strategy on how to gain resources. In the context of the job search process, networking behaviors refer to individuals' proactive actions aiming at acquiring information, leads, or suggestions on obtaining a job through friends or other people in their social networks [22].

In the past twenty years, it is very popular to examine the characteristics of networking behaviors in the job search process. Zottoli and Wanous [23] defined networking as a typical informal job search behavior, in the perspective of formal-informal classification. That is to say, in contrast to formal job search behavior, which relies on formal intermediaries such as campus recruitment or employment agencies, which are built only for recruitment purposes, informal job search behaviors do not need the help from those formal intermediaries but contact the persons they are acquainted with for new opportunities. Saks and Ashforth [24] also made a great contribution to the characteristics of networking behaviors in the job search process, by stating that networking is a typical preparatory job search behavior, according to the preparatory-active classification. However, Hoye et al. [20] pointed out that networking could be classified as both preparatory behaviors and active behaviors because the job search process could be divided into two stages. As such, at the beginning of the job search process, individuals experience a preparatory job search stage, in which they collect relevant information regarding potential jobs through networking. Following this, individuals will be actively contacting prospective employers in order to get a new job, which refers to active behaviors. 


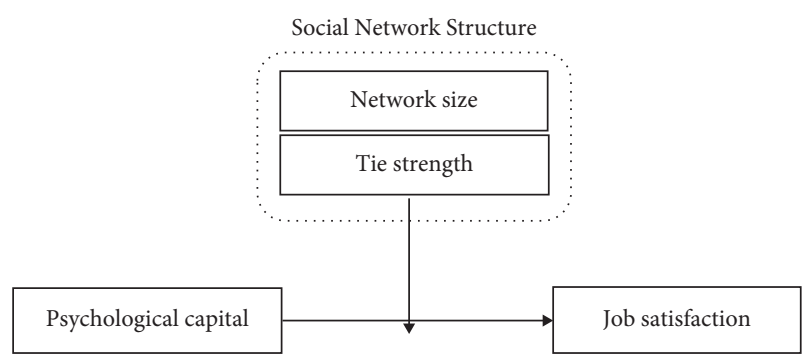

Figure 1: Model logic diagram.

Besides the research on characteristics of networking behaviors, scholars also paid great attention to the frequency of networking behaviors in the job search process. Kanfer et al. [10] used general job search intensity to describe the frequency of combined job search behaviors adopted by individuals in the process. The composition of general job search behaviors involves not only networking behaviors (e.g., turning to friends for help) but also other behaviors (e.g., through advertisements on newspapers, TV, or the Internet). The frequency and intensity of networking behaviors are reported to be positively related to job search outcomes [10]. Thus, the prior research considers networking as a specific job search behavior, differing from others, and this provides the theoretical insight for our current study and a sufficient approach to support our following research.

2.2. Psychological Capital and Job Satisfaction. Psychological capital, which refers to "an individual's positive psychological state of development [25]," consists of four psychological resources, i.e., "(1) having confidence (self-efficacy) to take on and put in the necessary effort to succeed at challenging tasks; (2) making a positive attribution (optimism) about succeeding now and in the future; (3) persevering toward goals and, when necessary, redirecting paths to goals (hope) in order to succeed; and (4) when beset by problems and adversity, sustaining and bouncing back and even beyond (resilience) to attain success [26]." As psychological capital is "state-like," it is also malleable and open to development $[27,28]$. A large number of studies had proved that psychological capital has positive impacts on various individuals' attitudes or behaviors, such as performance, engagement, satisfaction, well-being, and citizenship behavior [29-31]. In the context of job search behaviors, the individuals with higher psychological capital are likely to be more confident with themselves in the job-hunting process and ultimately obtain more job offers, compared to the individuals with lower psychological capital. Subsequently, those individuals with higher psychological capital will be likely to be satisfied with their jobs. Thus, we predict the following.

Hypothesis 1. Psychological capital is positively related to job satisfaction.

2.3. Social Network Structure as a Moderator. In the literature, social network theorists emphasized the importance of the social network structure, which was defined as the formal structure of the ties or relationships making up the social network [20], and proposed it as an essential source of social capital $[32,33]$. On the basis of this point, we expect that social network structure will influence the relationship between psychological capital and job satisfaction. According to the prior studies, social network structure consists of two important components, i.e., network size and tie strength. First of all, network size refers to the total number of persons to whom an individual is tied [34]. According to Hoye et al. [20], network size is positively associated with time spent networking. The individuals, whose social network size is large, always need to spend more time on networking behaviors, because they need to contact more people in their networks. Thus, the job seekers with larger networks are likely to ask more persons for help and collect job-related information from them. The more people job seekers contact, the more job opportunities they could obtain. The more people job seekers ask for help, the greater progress they will make in the job search process.

Thus, in the context of large network size, job seekers are likely to rely heavily on the information or opportunities networks bring to them, which will weaken the effects of psychological capital on the job search process. In contrast, job seekers, who just have a small social network, can only have limited friends or acquaintances who can help and then need mainly to seek a job on their own. Therefore, in the context of a small network size, job seekers' internal psychological capitals play a more significant role in the acquisition of job-related information and job offers. Thus, we propose the following.

Hypothesis 2. Network size moderates the relationship between psychological capital and job satisfaction, such that the relationship is more positive for job seekers with smaller social networks.

Besides network size, the other important element of social network structure is the strength of the ties in networks $[2,35,36]$. Tie strength refers to the closeness of the interpersonal relationship between the individual and the other persons in social networks [2]. For instance, parents, relatives, or close friends represent strong ties in social networks, while seldom-contacted friends could be an example of weak ties [20]. Reingen and Kernan [37] stated that individuals are always likely to contact those people with whom they are much more familiar to gather information regarding job vacancies in the job-hunting process. In contrast, the individuals have fewer interactions with those people they are not familiar with and could obtain little help from them. The previous research on marketing also claimed that individuals are more inclined to gather information from strong ties rather than weak ties [37, 38]. Hoye et al. [20] collected empirical evidence to find out that individuals with strong ties in social networks always spend more time on networking behaviors in order to acquire adequate information when they are looking for a new job.

Based on these, in the context of strong ties, the job seekers will do endeavor to contact those close friends for help, which means that they are likely to rely heavily on networking behaviors and ignore the role of psychological 
capital in the job search process. In contrast, job seekers with just weak ties could not obtain adequate information and enough help from their friends; thus, they are more likely to get job-related information from other sources (e.g., via employment advertising or job sites.) by themselves. In this situation, psychological capitals help them to have a positive and optimistic state to be confronted with difficulties and fierce competition in the job search process. Taken together, we predict the following.

Hypothesis 3. Tie strength moderates the relationship between psychological capitals and job satisfaction, such that the relationship is more positive for job seekers with weaker ties in their social networks.

\section{Methods}

3.1. Sample and Procedure. Our participants were university undergraduate students who soon graduate from 19 universities in Beijing city, Shandong Province, and Jiangsu Province, which are all located in Eastern China. Selection criteria for inclusion in the survey were that students were in the fourth year of their undergraduate studies and decided to work after graduation and had obtained at least one job offer till now. We then contacted the potential respondents and invited them to participate in the survey as a volunteer with the guarantee of confidentiality and anonymity. If the respondents agreed to participate, we asked them to choose to answer the questions via e-mail or we-chat (i.e., a free communication application in China), and the questionnaires were sent to them via the platform they chose.

To alleviate potential common method biases [39], survey data was collected in a two-wave longitudinal design. The literature showed the advantages of collecting data for more than one round of data within a long period [40]. As Gollob and Reichardt [41] stated, "no one time lag by itself can give a complete understanding of a variable's effects." Thus, the data was collected at two different time points within one month. At time 1, respondents completed measures of psychological capital, network size, and tie strength. One month later, at time 2, students were invited to finish the measurement of job satisfaction. In total, 403 students were invited to participate in the study, and accordingly, in time 2, a total of 378 questionnaires was acquired, yielding a response rate of $93.7 \%$. Finally, 344 valid types of data were selected and adopted in this study.

3.2. Variable Designing and Measurement. All variables in this study were measured by adopting a five-point Likert scale, which ranges from 1 (strongly disagree) to 5 (strongly agree). Brislin's [42] back-translation method was used to translate English items into Chinese. Some items are adapted to the uniqueness of Chinese characteristics and culture.

3.2.1. Independent Variable. The dependent variable is psychological capital. According to Luthans et al.'s [26] definition, psychological capital is categorized into four elements, self-efficacy, optimism, hope, and resilience. The measurement developed by Luthans et al. [26] was adapted to fit the Chinese context and includes 24 items. Some sample items for psychological capital consist of the following: "I feel confident helping to set targets/goals in my work area" (self-efficacy); "I always look on the bright side of things regarding my job" (optimism); "If I should find myself in a jam at work, I could think of many ways to get out of it" (hope); "I usually manage difficulties one way or another at work" (resilience).

3.2.2. Dependent Variable. The dependent variable is job satisfaction. Job satisfaction was measured by three items, which were adapted from Bharati and Chaudary [43]. The first item was "the current job offers I got are what I expect." The second item was "I hope that I can have a bright future in my job, which I choose from all my job offers." The third item was "I believe that I make a right decision in choice of the job offers."

3.2.3. Moderator. As discussed above, social network structure was chosen as a moderator in this study. According to Hoye et al. [20], social network structure consists of two components: network size and tie strength. As for the measurement of network size, 3 items adapted from Hoye et al. [20] were used. The first item is "I know a lot of people who might help me find a job." The second item is "I can count on many relatives, friends, or acquaintances for information about jobs." The third item is "I have connections I can talk to help me find a job." On the other hand, three items, adapted from Hoye et al. [20], were also chosen for the measurement of tie strength. The first item is "most people who might help me find a job are people I know very well, such as family or friends." The second item is "most people who might help me find a job are people I often talk to." The third item is "most people who might help me find a job are people I feel comfortable talking to, even about touchy subjects".

3.2.4. Control Variables. The control variables consist of gender, single child, student leader, CPC member, university classification, and major classification. We do not include age and education, as the participants of this study were all in their final year of undergraduate period, and have similar ages and same educational background. For education background, we also use university classification, which represents the level of the university and major classification, which represents different categories of major to distinct these respondents. The variable' scaling and statistical description are as shown in Table 1.

3.3. Model. In the process of data analysis and hypotheses test, factor analysis and hierarchical regression model were used.

3.3.1. Factor Analysis. Factor analysis is a widely used explorative methodology of statistics, aiming at grouping similar variables into the same factor. It uses the data 
TABLE 1: Control variable scaling and statistics.

\begin{tabular}{lccc}
\hline Category & Scaling & No. & $\begin{array}{c}\text { Ratio } \\
(\%)\end{array}$ \\
\hline Gender & $0=$ male & 131 & 38.1 \\
Single child & $1=$ female & 213 & 61.9 \\
& $1=$ yes & 211 & 61.3 \\
Student leader & $0=$ no & 133 & 38.7 \\
& $1=$ yes & 165 & 48 \\
CPC member & $0=$ no & 179 & 52 \\
& $1=$ yes & 141 & 41 \\
University & $0=$ no & 203 & 59 \\
classification & $1=$ institute & 4 & 1.2 \\
& $2=985$ projects & 62 & 18 \\
& $3=211$ projects & 131 & 38.1 \\
& $4=$ normal university & 147 & 42.7 \\
Major classification & $1=$ humanity and social & 115 & 33.4 \\
& science & & \\
& $2=$ natural science & 24 & 7 \\
& $3=$ technology & 62 & 18 \\
& $4=$ management & 129 & 37.5 \\
& $5=$ others & 14 & 4.1 \\
\hline
\end{tabular}

correlation matrix to identify the latent variables. When conducting the analysis of data, factor analysis is always used to reduce the dimension of the dataset at the beginning. Normally, factors will be rotated after it has been extracted, in order to decrease the number of the variables in the regression model. Moreover, factor analysis is always adopted to cope with the problems of multicollinearity in regression analysis. In the following section, Varimax, as a popular rotation method, will be used to simplify the interpretation of each factor in the model. According to Pereira et al. [44], the steps conducted in exploratory factor analysis were stated as follows: "(1) collect data: choose relevant variables used in the regression model; (2) extract initial factors; (3) choose the number of factors to retain; (4) choose estimation method and estimate model; (5) rotate and interpret the results" [44].

According to $[45,46]$, the fundamental model for factor analysis is stated as follows:

$$
\begin{aligned}
& X=A F+B, \\
& x_{1}=a_{11} F_{1}+a_{12} F_{2}+a_{1 m} F_{m}+\varepsilon_{1}, \\
& x_{1}=a_{21} F_{1}+a_{22} F_{2}+a_{2 m} F_{m}+\varepsilon_{2}, \\
& x_{1}=a_{p 1} F_{1}+a_{p 2} F_{2}+a_{p m} F_{m}+\varepsilon_{p}, \\
& x_{i}=a_{i 1} F_{1}+a_{i 2} F_{2}+a_{i m} F_{m}+\varepsilon_{i} .
\end{aligned}
$$

In the model above $[45,46], X$ refers to the observable random vector while $\mathrm{F}$ refers to the common factor of $X$. $A$ refers to the coefficient of $F$ while $B$ refers to the special factor of $X . a_{i j}$ refers to the correlation coefficient while $\varepsilon_{i}$ refers to the error factor.

To conduct factor analysis $[45,46]$, we need to normalize the $X$ matrix, in order to ensure that the mean value equals 0 and the variance equals 1 . Subsequently, $F$ and $\varepsilon_{i}$ should be assumed to be independent. Thirdly, we need to calculate the correlation coefficient matrix (i.e., $R=(r i j) p * p$ ) and its latent root. Ultimately, the number of the factors should be decided, and the common factors will be acquired by rotating the loading matrix.

3.3.2. Moderation Effect on Hierarchical Regression Analysis. Hierarchical regression analysis is a commonly used statistical methodology, which helps to quantify the relationships between different variables. In order to testify the relationship between the variables in the hypotheses above, it is necessary to conduct a hierarchical regression analysis to make sure whether the hypotheses are supported. In the process of a hierarchical regression model, we can decide what predictors should be entered into the model, and we also need to determine in what step we enter each variable. Normally, the logical and theoretical considerations will influence the order we enter each predictor.

The most important aim of this study is to decide the interaction of social network structure and psychological capital and its effect on job satisfaction. As such, we need to examine the moderation effect of social network structure via a hierarchical regression model. Hence, the model equation of the moderation effect is stated as follows:

$$
Y=b 0+b 1 X+b 2 W+b 3 X W .
$$

In the model, $Y$ refers to the dependent variable while $X$ refers to the independent variable. $W$ refers to the moderator variable. Here, $b 0$ is the intercept; $b 1$ refers to the regression coefficient of $X$ on $Y ; b 2$ refers to the regression coefficient of $W$ on $Y ; b 3$ refers to the regression coefficient of the interaction between $X$ and $W$ on $Y$. The relationship between these variables is shown in Figure 2.

In order to calculate the conditional effects of the moderator, the model equation should be written as $Y=a+b X$. Hence, after grouping the terms to form $Y=a+b X$, we got the following equation model:

$$
Y=(b 0+b 2 W)+(b 1+b 3 W) X .
$$

Here, $b 1+b 3 W$ represents the direct effect of $X$ on $Y$, conditional on $W$. In the following part of the hypotheses test, we conducted the hierarchical regression analysis by using SPSS 24.0. We will enter control variables, independent variable (i.e., psychological capital), dependent variable (i.e., job satisfaction), and moderation variables (i.e., network size and tie strength in the social network) into different steps in the model, in order to examine the moderation effect of network size and tie strength on the relationship between psychological capital and job satisfaction.

\section{Results and Analysis}

4.1. Analytical Strategy and Descriptive Statistics. In order to test the effect of psychological capital on job satisfaction and the moderation effect of social network structure on this relationship, the hierarchical regression model was adopted to test the hypotheses. In order to avoid multicollinearity, all variables in the study were grand-mean-centered. To make sure reliability and validity, relevant tests were also conducted. Firstly, the test results told us that the Cronbach 


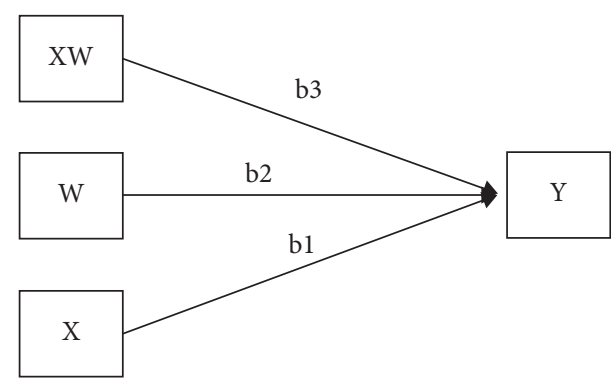

FIGURE 2: Model of moderation effect in hierarchical regression analysis.

Alpha Coefficient is 0.886 , which shows that the internal consistency is great. Secondly, it is found that the KaiserMeyer-Olkin is 0.869, while the significance level of Bartlett's test of sphericity is 0.000 , which shows a high level of validity (Tables 2 and 3). Means, standard deviations, and correlations among all variables are presented in Table 4.

4.2. Exploratory Factor Analysis. In this study, we collected the data for four major variables (i.e., psychological capital, job satisfaction, network size, and tie strength) from the same source, although it has been done two times within one month. This could lead to common method problems, which exist if only one factor emerged or if a single factor accounted for the majority of the variance among the variables. Thus, it is necessary to assess common method variance among these four variables. We conducted a principal component exploratory factor analysis, which is suggested by Podsakoff and Organ [47]. The results showed that four factors had eigenvalues greater than one and explained $79.6 \%$ of the variance (Table 5). According to Table 5, it is obvious that the factor loadings are all higher than 0.75 , which indicated good internal reliability. Thus, these four variables will be all used in the following hypotheses tests.

\subsection{Results of Hypotheses Test}

4.3.1. Results of Test of Hypothesis 1. To test the three hypotheses proposed above, a hierarchical regression analysis was performed. To test Hypothesis 1, we created a two-step model by SPSS 24.0. We entered control variables and job satisfaction (dependent variable) in the first step. Subsequently, we added psychological capital (independent variable) into the equation in the second step. The results showed that $R^{2}$ significantly increased in step 2 (regression coefficient $=0.374, p<0.001$ ), compared to the counterpart in step 1, which represents the positive impact of psychological capital on job satisfaction and thus supports $\mathrm{Hy}-$ pothesis 1 (Table 6).

4.3.2. Results of Test of Hypothesis 2. To test the moderating effect of social network structure on the relationship between psychological capital and job satisfaction, hierarchical regression analysis was, respectively, performed for network
TABLE 2: The reliability of the survey.

\begin{tabular}{lc}
\hline Number of the items & Cronbach's $\alpha$ coefficient \\
\hline 33 & 0.886
\end{tabular}

size and tie strength. To begin with the test of Hypothesis 2, the control variables were entered as well as job satisfaction (dependent variable). Then, psychological capital (independent variable) was added to the equation in the second step. Finally, we added the interaction between psychological capital and social network size in the third step. Meanwhile, in order to cope with multicollinearity problems, we followed Aiken and West's [48] suggestion in the moderated regression model that the dichotomous variables were effects coded and continuous variables were centered.

As indicated in step 3 of Table 7, the results showed that $R^{2}$ increased from 0.173 to 0.258 , which slightly increased the variance explained. This supports Hypothesis 2 stating that social network size moderates the relationship between psychological capital and job satisfaction (regression coefficient $=-0.306, p<0.001$ ). Besides this, Figure 3 also shows that the positive impact of psychological capital on job satisfaction was stronger when job seekers have small size networks than when job seekers have large size networks. Hence, Hypothesis 2 was supported.

4.3.3. Results of Test of Hypothesis 3. To test the moderating effect of social network tie strength on the relationship between psychological capital and job satisfaction, we followed the same procedure conducted above. We entered control variables and job satisfaction (dependent variable) in the first step, psychological capital (independent variable) in the second step, and the interaction between psychological capital and tie strength in social networks in the third step. The results (Table 8 ) indicate that $R^{2}$ increased from 0.182 to 0.258, which supports Hypothesis 3 (regression coefficient $=-0.291, p<0.001)$. Furthermore, Figure 4 shows that the positive impact of psychological capital on job satisfaction was stronger when job seekers have weak ties than when job seekers have strong ties. Thus, Hypothesis 3 was supported.

\section{Discussion}

Extending the prior job search research, we applied a social network perspective to explore whether social network structure moderates the impact of psychological capital on job satisfaction. By using the data from a two-wave longitudinal design, the results show that network size moderates the relationship between psychological capital and job satisfaction, such that the relationship is more positive for job seekers with small social networks. Moreover, tie strength also moderates the relationship between psychological capital and job satisfaction, such that the relationship is more positive for job seekers with weaker ties in their social networks. 
TABLE 3: The reliability of each item in the survey.

\begin{tabular}{|c|c|c|c|c|}
\hline Variable & Item & CITC & $\alpha$ coefficient after deleting this item & $\alpha$ coefficient \\
\hline \multirow{6}{*}{ Self-efficacy (one dimension of psychological capital) } & SE1 & 0.755 & 0.903 & \multirow{6}{*}{0.917} \\
\hline & SE2 & 0.756 & 0.903 & \\
\hline & SE3 & 0.776 & 0.900 & \\
\hline & SE4 & 0.772 & 0.901 & \\
\hline & SE5 & 0.777 & 0.900 & \\
\hline & SE6 & 0.752 & 0.904 & \\
\hline \multirow{6}{*}{ Hope (one dimension of psychological capital) } & $\mathrm{H} 1$ & 0.774 & 0.922 & \multirow{6}{*}{0.931} \\
\hline & $\mathrm{H} 2$ & 0.818 & 0.916 & \\
\hline & $\mathrm{H} 3$ & 0.806 & 0.918 & \\
\hline & $\mathrm{H} 4$ & 0.739 & 0.926 & \\
\hline & H5 & 0.846 & 0.913 & \\
\hline & H6 & 0.813 & 0.917 & \\
\hline \multirow{6}{*}{ Resilience (one dimension of psychological capital) } & $\mathrm{R} 1$ & 0.886 & 0.954 & \multirow{6}{*}{0.962} \\
\hline & $\mathrm{R} 2$ & 0.889 & 0.954 & \\
\hline & R3 & 0.909 & 0.952 & \\
\hline & $\mathrm{R} 4$ & 0.866 & 0.956 & \\
\hline & R5 & 0.870 & 0.956 & \\
\hline & R6 & 0.854 & 0.958 & \\
\hline \multirow{6}{*}{ Optimism (one dimension of psychological capital) } & $\mathrm{O} 1$ & 0.822 & 0.956 & \multirow{6}{*}{0.958} \\
\hline & $\mathrm{O} 2$ & 0.825 & 0.955 & \\
\hline & $\mathrm{O} 3$ & 0.914 & 0.945 & \\
\hline & $\mathrm{O} 4$ & 0.906 & 0.946 & \\
\hline & O5 & 0.861 & 0.951 & \\
\hline & O6 & 0.884 & 0.949 & \\
\hline \multirow{3}{*}{ Job satisfaction } & JS1 & 0.636 & 0.723 & \multirow{4}{*}{0.794} \\
\hline & JS2 & 0.599 & 0.758 & \\
\hline & JS3 & 0.680 & 0.677 & \\
\hline \multirow{3}{*}{ Network size } & NS1 & 0.805 & 0.906 & \\
\hline & NS2 & 0.896 & 0.832 & \multirow[t]{2}{*}{0.918} \\
\hline & NS3 & 0.805 & 0.907 & \\
\hline \multirow{3}{*}{ Tie strength } & TS1 & 0.863 & 0.919 & \multirow{3}{*}{0.939} \\
\hline & TS2 & 0.897 & 0.893 & \\
\hline & TS3 & 0.860 & 0.921 & \\
\hline
\end{tabular}

TABLE 4: Means, SDs, and correlations of study variables.

\begin{tabular}{|c|c|c|c|c|c|c|c|c|c|c|c|c|}
\hline Factor & Mean & $\mathrm{SD}$ & 1 & 2 & 3 & 4 & 5 & 6 & 7 & 8 & 9 & 10 \\
\hline (1) Gender & 0.616 & 0.487 & 1 & & & & & & & & & \\
\hline (2) Single child & 0.384 & 0.487 & $0.168^{* *}$ & - & & & & & & & & \\
\hline (3) Student leader & 0.517 & 0.500 & 0.063 & 0.068 & - & & & & & & & \\
\hline (4) CPC member & 0.579 & 0.495 & 0.041 & 0.020 & $0.330^{* *}$ & - & & & & & & \\
\hline (5) University classification & 3.201 & 0.803 & $0.130^{*}$ & 0.064 & 0.017 & $0.147^{* *}$ & - & & & & & \\
\hline (6) Major classification & 2.683 & 1.373 & -0.078 & -0.005 & 0.023 & $0.133^{*}$ & 0.058 & - & & & & \\
\hline (7) Psychological capital & 3.427 & 0.631 & -0.026 & -0.047 & -0.045 & 0.104 & -0.019 & 0.097 & - & & & \\
\hline (8) Job satisfaction & 3.363 & 0.693 & $-0.144^{*}$ & -0.023 & -0.025 & 0.046 & -0.023 & 0.079 & $0.381^{* *}$ & - & & \\
\hline (9) Network size & 3.247 & 1.145 & -0.068 & 0.068 & 0.046 & 0.042 & -0.001 & 0.094 & $0.203^{* *}$ & $0.179^{* *}$ & - & \\
\hline (10) Tie & 2.949 & 1.148 & -0.072 & -0.048 & 0.043 & -0.040 & 0.012 & 0.011 & 0.063 & -0.102 & $0.159^{* *}$ & - \\
\hline
\end{tabular}

Note: $N=344 .{ }^{*} P<0.05,{ }^{* *} P<0.01$, and ${ }^{* * *} P<0.001$.

This study results in several essential findings which contribute to the literature regarding social networks and job search. First, psychological capital is a type of invisible resource, and it can help job seekers to have better job search behaviors and then good employment outcomes, e.g., acquirement of satisfactory job offers. It is well known that China has a large population and the competition in the job market is very fierce. Thus, job seekers with higher psychological capital are more likely to succeed in the competition. This finding is consistent with previous research on the positive effect of psychological capital on employees' attitudes or behaviors (e.g., satisfaction, performance, and well-being) [29-31].

Second, social network structure, i.e., network size and tie strength, is found to be a moderator of the relationship between psychological capital and job satisfaction. Specifically, the impact of psychological capital on job satisfaction will be stronger, when job seekers have a smaller network or 
TABLE 5: Results of exploratory factor analysis (EFA) in the study.

\begin{tabular}{|c|c|c|c|c|c|}
\hline \multirow{2}{*}{ Variables } & \multirow{2}{*}{ Items } & \multicolumn{4}{|c|}{ Factors } \\
\hline & & 1 & 2 & 3 & 4 \\
\hline \multirow{24}{*}{ Psychological capital } & $\mathrm{PC} 1$ & 0.816 & & & \\
\hline & PC2 & 0.832 & & & \\
\hline & PC3 & 0.844 & & & \\
\hline & PC4 & 0.832 & & & \\
\hline & PC5 & 0.846 & & & \\
\hline & PC6 & 0.820 & & & \\
\hline & PC7 & 0.837 & & & \\
\hline & PC8 & 0.859 & & & \\
\hline & PC9 & 0.860 & & & \\
\hline & PC10 & 0.808 & & & \\
\hline & PC11 & 0.883 & & & \\
\hline & PC12 & 0.860 & & & \\
\hline & PC13 & 0.906 & & & \\
\hline & PC14 & 0.913 & & & \\
\hline & PC15 & 0.933 & & & \\
\hline & PC16 & 0.898 & & & \\
\hline & PC17 & 0.903 & & & \\
\hline & PC18 & 0.890 & & & \\
\hline & PC19 & 0.859 & & & \\
\hline & PC20 & 0.882 & & & \\
\hline & PC21 & 0.931 & & & \\
\hline & PC22 & 0.922 & & & \\
\hline & PC23 & 0.886 & & & \\
\hline & PC24 & 0.908 & & & \\
\hline \multirow{4}{*}{ Job satisfaction } & JS1 & & 0.792 & & \\
\hline & JS2 & & 0.788 & & \\
\hline & JS3 & & 0.842 & & \\
\hline & NS1 & & & 0.891 & \\
\hline \multirow[t]{2}{*}{ Network size } & NS2 & & & 0.945 & \\
\hline & NS3 & & & 0.893 & \\
\hline \multirow{3}{*}{ Tie strength } & $\mathrm{T} 1$ & & & & 0.932 \\
\hline & $\mathrm{T} 2$ & & & & 0.944 \\
\hline & $\mathrm{T} 3$ & & & & 0.933 \\
\hline
\end{tabular}

TABLE 6: Hierarchical regression of the influence of psychological capital on job satisfaction.

\begin{tabular}{lcc}
\hline \multirow{2}{*}{ Predictor } & \multicolumn{2}{c}{ Job satisfaction } \\
& Step 1 & Step 2 \\
\hline Control variables & & \\
Gender & $-0.137^{*}$ & $-0.135^{* *}$ \\
Single child & 0.003 & 0.018 \\
Student leader & -0.037 & -0.005 \\
CPC member & 0.058 & 0.010 \\
University classification & -0.017 & -0.003 \\
Major classification & 0.062 & 0.031 \\
\hline Independent variable & & \\
Psychological capital & & $0.374^{* * *}$ \\
$R^{2}$ & 0.029 & 0.164 \\
$\triangle R^{2}$ & 0.011 & 0.147 \\
$F$ & 1.652 & $9.430^{* * *}$ \\
\hline
\end{tabular}

Note: $N=344$. The values in the table are standardized beta weights (b). ${ }^{*} p<0.05,{ }^{* *} p<0.01$, and ${ }^{* * *} p<0.001$.

when job seekers have weaker ties in social networks. This is an interesting and important finding, which indicates the interaction between social network structure and
TABLE 7: Hierarchical regression of moderating effect of network size on the relationship between psychological capital and job satisfaction.

\begin{tabular}{|c|c|c|c|}
\hline \multirow{2}{*}{ Variables } & \multicolumn{3}{|c|}{ Job satisfaction } \\
\hline & Step 1 & Step 2 & Step 3 \\
\hline \multicolumn{4}{|l|}{ Control variables } \\
\hline Gender & $-0.137^{*}$ & $-0.127^{*}$ & $-0.104^{*}$ \\
\hline Single child & 0.003 & 0.009 & -0.007 \\
\hline Student leader & -0.037 & -0.010 & -0.023 \\
\hline CPC member & 0.058 & 0.011 & 0.005 \\
\hline University classification & -0.017 & -0.003 & -0.005 \\
\hline Major classification & 0.062 & 0.024 & 0.015 \\
\hline \multicolumn{4}{|l|}{ Independent variable } \\
\hline Psychological capital & & $0.354^{* * *}$ & $0.264^{* * *}$ \\
\hline \multicolumn{4}{|l|}{ Moderator } \\
\hline Network size & & 0.096 & $0.124^{*}$ \\
\hline \multicolumn{4}{|l|}{ Interaction } \\
\hline $\begin{array}{l}\text { Psychological capital } \times \text { network } \\
\text { size }\end{array}$ & & & $-0.306^{* * *}$ \\
\hline$R^{2}$ & 0.029 & 0.173 & 0.258 \\
\hline$\triangle R^{2}$ & 0.011 & 0.153 & 0.238 \\
\hline$F$ & 1.652 & $8.748^{* * *}$ & $12.894^{* * *}$ \\
\hline
\end{tabular}

Note: $N=344 .{ }^{*} p<0.05,{ }^{* *} p<0.01$, and ${ }^{* * *} p<0.001$.

psychological capital. Prior research showed the important role of social networks in job search in Chinese society. It is reported that Chinese guanxi (i.e., interpersonal relationship between two individuals) [49], which is a typical social network in China, could help individuals to get job offers from a company and obtain advantages and benefits through guanxi HRM practices (i.e., HRM practices based on guanxi) [50, 51]. The findings in this study proved the formidable influence of social networks in Chinese society again, which echoes the findings in prior research [49-51]. That is to say, if job seekers have strong ties or large network sizes, the influence of psychological capital on job search behaviors and outcomes will be weakened.

Third, the findings in this study also showed that different personal resources (e.g., psychological capital and social capital) are helpful for job seekers to obtain satisfactory job offers in the job search process. In the last century, social networks, which are considered the most important personal resource, significantly influence almost every aspect of Chinese people's life. As Xiong et al. pointed out, one's decision will be always affected by their neighbors in social networks [52, 53]; e.g., users' decisions are often affected by the existing ratings on social media [54]. However, the economic reform and society development lead to the perfection of legal regulation and policies and transparency of the procedures. This results in the declining significance of social networks in Chinese society. That is to say, social networks as a part of social capital are no longer the only personal resource that can determine whether Chinese people could succeed in the competition, and this represents the development of the society. On the other hand, it is notable that job seekers who have large network sizes or strong ties still rely heavily on the help of social 


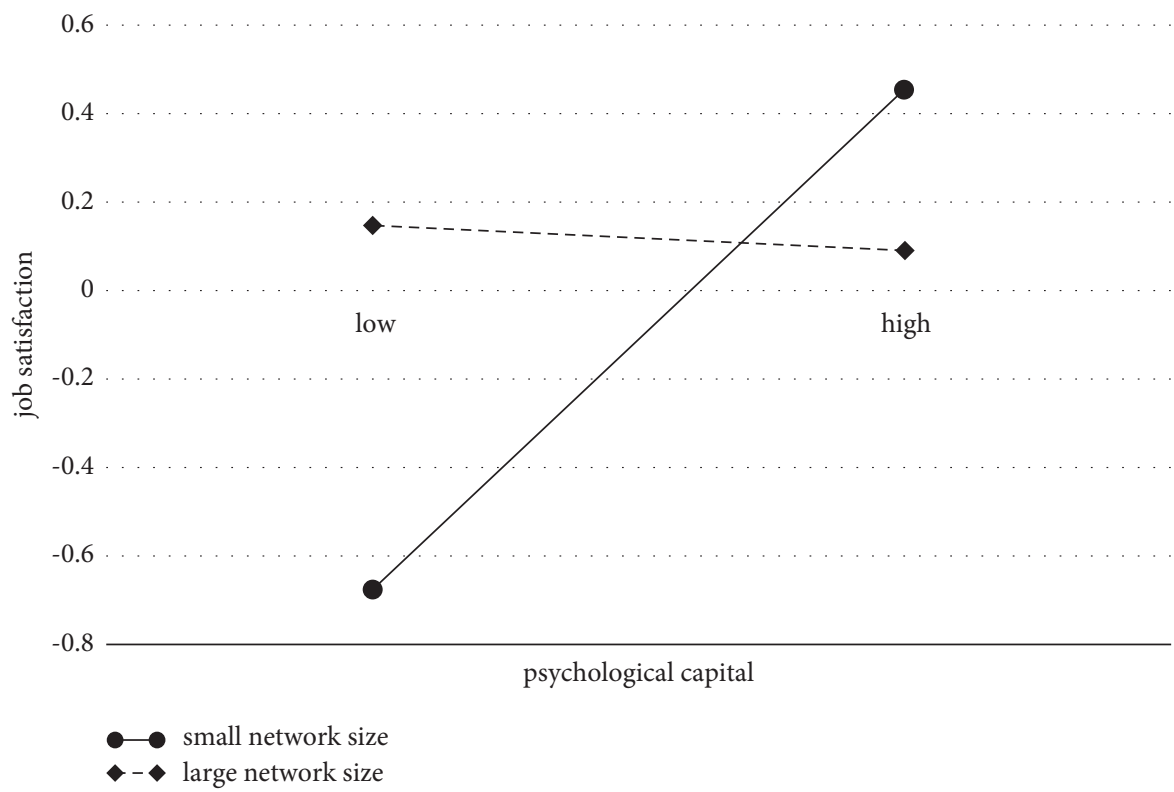

FIGURE 3: Interaction of psychological capital and network size on job satisfaction.

TABLE 8: Hierarchical regression of moderating effect of tie strength on the relationship between psychological capital and job satisfaction.

\begin{tabular}{|c|c|c|c|}
\hline \multirow{2}{*}{ Variables } & \multicolumn{3}{|c|}{ Job satisfaction } \\
\hline & Step 1 & Step 2 & Step 3 \\
\hline \multicolumn{4}{|l|}{ Control variables } \\
\hline Gender & $-0.137^{*}$ & $-0.144^{* *}$ & $-0.144^{* *}$ \\
\hline Single child & 0.003 & 0.012 & 0.004 \\
\hline Student leader & -0.037 & 0.005 & 0.009 \\
\hline CPC member & 0.058 & 0.000 & -0.020 \\
\hline University classification & -0.017 & 0.002 & -0.026 \\
\hline Major classification & 0.062 & 0.032 & 0.040 \\
\hline \multicolumn{4}{|l|}{ Independent variable } \\
\hline Psychological capital & & $0.383^{* * *}$ & $0.299^{* * *}$ \\
\hline \multicolumn{4}{|l|}{ Moderator } \\
\hline Tie strength & & $-0.136^{* *}$ & $-0.133^{* *}$ \\
\hline \multicolumn{4}{|l|}{ Interaction } \\
\hline Psychological capital $\times$ tie strength & & & $-0.291^{* * *}$ \\
\hline$R^{2}$ & 0.029 & 0.182 & 0.258 \\
\hline$\triangle R^{2}$ & 0.011 & 0.163 & 0.238 \\
\hline$F$ & 1.652 & $9.342^{* * *}$ & $12.925^{* * *}$ \\
\hline
\end{tabular}

Note: $N=344 .{ }^{*} p<0.05,{ }^{* *} p<0.01$, and ${ }^{* * *} p<0.001$.

networks in the job search process. Every coin has two sides; everything has both good and bad aspects. For instance, it is proper for job seekers to collect more information through social networks. However, it is inappropriate for those job seekers to join a company through informal social networks by violating procedural justice because this kind of practice based on informal social networks leads to the competitors' perceptions of unfairness [50, 51]. Therefore, it is important for Chinese enterprises and all other organizations to take action to ensure justice in the recruitment process. For instance, managers could ensure a fair procedure in recruitment and more transparent decision making, in order to reduce the factors, which lead to unfairness $[55,56]$.

The study is not without its limitations. Firstly, this study adopted a convenience sample, including only undergraduates who are about to graduate. Future studies may test the hypothesized model with various respondents, such as the employees who have been working for a period. Secondly, due to the limited time for all empirical studies, we collected all the data for the survey within one month. Future studies could consider collecting the data within a longer period, e.g., collecting the second time data when the graduates start their work for a period. 


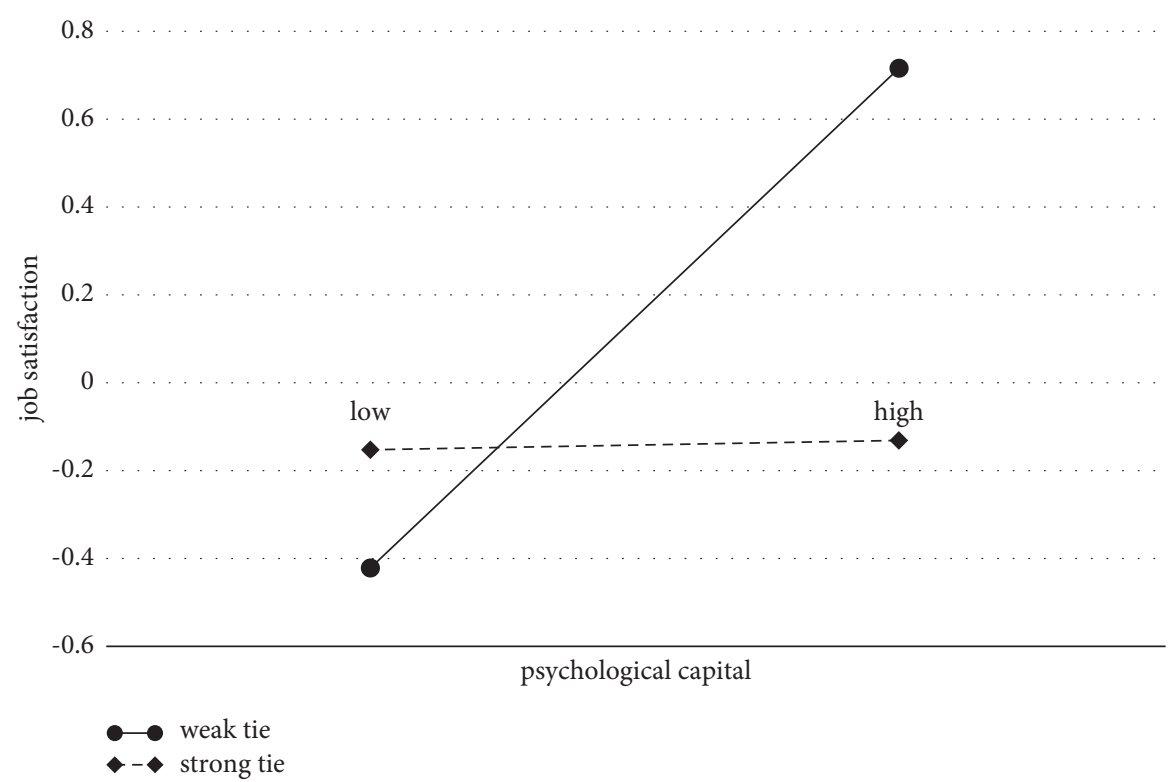

FIgURE 4: Interaction of psychological capital and tie strength on job satisfaction.

\section{Data Availability}

The data adopted to support the findings of the study are available from the corresponding author upon request.

\section{Conflicts of Interest}

The authors declare no conflicts of interest with respect to the research, authorship, and/or publication of this article.

\section{Acknowledgments}

This study was supported by the Fundamental Research Funds for the Central Universities (CUPL: 20ZFQ63001), the Social Science Foundation from the China University of Political Science and Law (10820366 and 20ZFQ63001), the National Science Foundation of China (71874205), and the National Social Science Foundation of China (20AZD071).

\section{References}

[1] R. Putnam, R. Leonardi, and R. Nanetti, Making Democracy Work: Civic Tradition in Modem Italy, Princeton University Press, New York, NY, USA, 1993.

[2] M. S. Granovetter, "The strength of weak ties," American Journal of Sociology, vol. 78, no. 6, pp. 1360-1380, 1973.

[3] Y. Sato, "Are Asian sociologies possible?: universalism versus particularism," in Facing an Unequal World: Challenges for a Global Sociology, M. Burawoy, M. Chang, and M. F. Hsieh, Eds., vol. 2, pp. 192-200, Institute of Sociology, Academia Sinica and Council of National Associations of International Sociological Association, Taipei, Taiwan, 2010.

[4] P. P. Li, "Social tie, social capital, and social behavior: toward an integrative model of informal exchange," Asia Pacific Journal of Management, vol. 24, no. 2, pp. 227-246, 2007.

[5] S. Horak, M. Taube, I. Yang, and K. Restel, "Two not of a kind: social network theory and informal social networks in east Asia," Asia Pacific Journal of Management, vol. 36, no. 2, pp. 349-372, 2019.
[6] F. McKee-Ryan, Z. Song, C. R. Wanberg, and A. J. Kinicki, "Psychological and physical well-being during unemployment: a meta-analytic study," Journal of Applied Psychology, vol. 90, no. 1, pp. 53-76, 2005.

[7] E. E. Brasher and P. Y. Chen, "Evaluation of success criteria in job search: a process perspective," Journal of Occupational and Organizational Psychology, vol. 72, no. 1, pp. 57-70, 1999.

[8] A. M. Saks and B. E. Ashforth, "Is job search related to employment quality?: it all depends on the fit," Journal of Applied Psychology, vol. 87, no. 4, pp. 646-654, 2002.

[9] C. R. Wanberg, L. M. Hough, and Z. Song, "Predictive validity of a multidisciplinary model of reemployment success," Journal of Applied Psychology, vol. 87, no. 6, pp. 1100-1120, 2002.

[10] R. Kanfer, C. R. Wanberg, and T. M. Kantrowitz, "Job search and employment: a personality-motivational analysis and meta-analytic review," Journal of Applied Psychology, vol. 86, no. 5, pp. 837-855, 2001.

[11] E. A. Locke, "The nature and causes of job satisfaction," in Hand Book of Industrial and Organizational Psychology, M. D. Dunnette, Ed., pp. 1297-1349, Rand McNally, Chicago, Illinois, 1976.

[12] E. Fabra Florit and L. E. Vila Lladosa, "Evaluation of the effects of education on job satisfaction: independent single-equation vs. structural equation models," International Advances in Economic Research, vol. 13, no. 2, pp. 157-170, 2007.

[13] G. Blau, "Testing a two-dimensional measure of job search behavior," Organizational Behavior and Human Decision Processes, vol. 59, no. 2, pp. 288-312, 1994.

[14] Z. H. Qiao, "The construct of graduates' employability and its effect on graduates' employment results," Psychological Development and Education, vol. 27, pp. 274-281, 2011, in Chinese.

[15] L. Y. Sun, “Analysis of college students' job-seeking situation in the new era and countermeasures to improve employment services: a case study of Nanjing university of science and technology," Employment Guidance, vol. 12, pp. 54-59, 2020.

[16] R. N. Bolles, What Color is Your Parachute?: A Practical Manual for Job-Hunters and Career-Changers, Ten Speed Press, Berkeley, CA, USA, 2006. 
[17] C. J. Collins and C. K. Stevens, "The relationship between early recruitment-related activities and the application decisions of new labor-market entrants: a brand equity approach to recruitment," Journal of Applied Psychology, vol. 87, pp. 1121$1133,2002$.

[18] G. V. Hoye and F. Lievens, "Recruitment-related information sources and organizational attractiveness: can something be done about negative publicity?" International Journal of Selection and Assessment, vol. 13, pp. pp179-187, 2005.

[19] A. Tziner, E. Vered, and L. Ophir, "Predictors of job search intensity among college graduates," Journal of Career Assessment, vol. 12, no. 3, pp. 332-344, 2004.

[20] G. V. Hoye, E. A. J. Hooft, and F. Lievens, "Networking as a job search behaviour: a social network perspective," Journal of Occupational and Organizational Psychology, vol. 82, pp. 661-682, 2009.

[21] M. L. Forret and T. W. Dougherty, "Correlates of networking behavior for managerial and professional employees," Group \& Organization Management, vol. 26, no. 3, pp. 283-311, 2001.

[22] C. R. Wanberg, R. Kanfer, and J. T. Banas, "Predictors and outcomes of networking intensity among unemployed job seekers," Journal of Applied Psychology, vol. 85, no. 4, pp. 491-503, 2000.

[23] M. A. Zottoli and J. P. Wanous, "Recruitment source research: current status and future directions," Human Resource Management Review, vol. 10, no. 4, pp. 353-382, 2000.

[24] A. M. Saks and B. E. Ashforth, "Change in job search behaviors and employment outcomes," Journal of Vocational Behavior, vol. 56, no. 2, pp. 277-287, 2000.

[25] A. Rego, F. Sousa, C. Marques, and M. P. E. Cunha, “Authentic leadership promoting employees' psychological capital and creativity," Journal of Business Research, vol. 65, no. 3, pp. 429-437, 2012.

[26] F. Luthans, C. M. Youssef, and B. J. Avolio, Psychological Capital, Oxford University Press, Oxford, UK, 2007.

[27] F. Luthans, J. B. Avey, B. J. Avolio, S. M. Norman, and G. M. Combs, "Psychological capital development: toward a micro-intervention," Journal of Organizational Behavior, vol. 27, no. 3, pp. 387-393, 2006.

[28] F. Luthans, B. J. Avolio, J. B. Avey, and S. M. Norman, "Positive psychological capital: measurement and relationship with performance and satisfaction," Personnel Psychology, vol. 60 , no. 3, pp. 541-572, 2007.

[29] F. Luthans, S. M. Norman, B. J. Avolio, and J. B. Avey, "The mediating role of psychological capital in the supportive organizational climate-employee performance relationship," Journal of Organizational Behavior, vol. 29, no. 2, pp. 219-238, 2008.

[30] J. B. Avey, T. S. Wernsing, and F. Luthans, "Can positive employees help positive organizational change?: impact of psychological capital and emotions on relevant attitudes and behaviors," The Journal of Applied Behavioral Science, vol. 44, no. 1, pp. 48-70, 2008.

[31] J. B. Avey, R. J. Reichard, F. Luthans, and K. H. Mhatre, "Meta-analysis of the impact of positive psychological capital on employee attitudes, behaviors, and performance," Human Resource Development Quarterly, vol. 22, no. 2, pp. 127-152, 2011.

[32] S. P. Borgatti and P. C. Foster, "The network paradigm in organizational research: a review and typology," Journal of Management, vol. 29, no. 6, pp. 991-1013, 2003.

[33] P. S. Adler and S.-W. Kwon, "Social capital: prospects for a new concept," Academy of Management Review, vol. 27, no. 1, pp. 17-40, 2002.
[34] S. E. Seibert, M. L. Kraimer, and R. C. Liden, "A social capital theory of career success," Academy of Management Journal, vol. 44, no. 2, pp. 219-237, 2001.

[35] M. S. Granovetter, Getting a Job: A Study of Contacts and Careers, University of Chicago Press, Chicago, Illinois, 2nd edition, 1995.

[36] D. W. Brown and A. M. Konrad, "Granovetter was right: the importance of weak ties to a contemporary job search," Group \& Organization Management, vol. 26, no. 4, pp. 434-462, 2001.

[37] P. H. Reingen and J. B. Kernan, "Analysis of referral networks in marketing: methods and illustration," Journal of Marketing Research, vol. 23, no. 4, pp. 370-378, 1986.

[38] M. C. Gilly, J. L. Graham, M. F. Wolfinbarger, and L. J. Yale, "A dyadic study of interpersonal information search," Journal of the Academy of Marketing Science, vol. 26, no. 2, pp. 83-100, 1998.

[39] P. M. Podsakoff, S. B. MacKenzie, and N. P. Podsakoff, "Sources of method bias in social science research and recommendations on how to control it," Annual Review of Psychology, vol. 63, no. 1, pp. 539-569, 2012.

[40] J. Hu, B. Erdogan, T. N. Bauer, K. Jiang, S. Liu, and Y. Li, "There are lots of big fish in this pond: the role of peer overqualification on task significance, perceived fit, and performance for overqualified employees," Journal of Applied Psychology, vol. 100, no. 4, pp. 1228-1238, 2015.

[41] H. F. Gollob and C. S. Reichardt, "Taking account of time lags in causal models," Child Development, vol. 58, no. 1, pp. 80-92, 1987.

[42] R. W. Brislin, "The wording and translation of research instrument," in Field Methods in Cross-Cultural Research, W. J. Lonner and J. W. Berry, Eds., pp. 137-164, Sage, Beverly Hills, CA, USA, 1986.

[43] P. Bharati and A. Chaudhury, "An empirical investigation of decision-making satisfaction in web-based decision support systems," Decision Support Systems, vol. 37, no. 2, pp. 187-197, 2004.

[44] V. Pereira, F. Tavares, P. Mihaylova, V. Mladenov, and P. Georgieva, "Factor analysis for finding invariant neural descriptors of human emotions," Complexity, vol. 2018, Article ID 6740846, 8 pages, 2018.

[45] K. Zhang, M. Hassan, M. Yahaya, and S. Yang, "Analysis of work-zone crashes using the ordered probit model with factor analysis in Egypt," Journal of Advanced Transportation, vol. 2018, Article ID 8570207, 10 pages, 2018.

[46] T. W. Anderson, An Introduction to Multivariate Statistical Analysis, John Wiley \& Sons, New York, NY, USA, 1984.

[47] P. M. Podsakoff and D. W. Organ, "Self-reports in organizational research: problems and prospects," Journal of Management, vol. 12, no. 4, pp. 531-544, 1986.

[48] L. S. Aiken and S. G. West, Multiple Regression: Testing and Interpreting Interactions, Sage, Newbury Park, CA, USA, 1991.

[49] C. C. Chen, X.-P. Chen, and S. Huang, "ChineseGuanxi: an integrative review and new directions for future research," Management and Organization Review, vol. 9, no. 1, pp. 167-207, 2013.

[50] D. Guthrie, "The declining significance of guanxi in China's economic transition," The China Quarterly, vol. 154, pp. 254-282, 1998.

[51] C. Chen, Y. Chen, and K. Xin, "Guanxi practices and trust in management: a procedural justice perspective," Organization Science, vol. 15, no. 2, pp. 200-209, 2004.

[52] F. Xiong, X. M. Wang, S. R. Pan, H. Yang, H. S. Wang, and C. Q. Zhang, "Social recommendation with evolutionary 
opinion dynamics," IEEE Transactions on Systems, Man, and Cybernetics: Systems, vol. 50, no. 10, pp. 3804-3816, 2020.

[53] Y. Hu, F. Xiong, S. Pan, X. Xiong, L. Wang, and H. Chen, "Bayesian personalized ranking based on multiple-layer neighborhoods," Information Sciences, vol. 542, pp. 156-176, 2021.

[54] F. Xiong, W. Shen, H. Chen, S. Pan, X. Wang, and Z. Yan, "Exploiting implicit influence from information propagation for social recommendation," IEEE Transactions on Cybernetics, vol. 50, no. 10, pp. 4186-4199, 2020.

[55] C. C. Chen and X.-P. Chen, "Negative externalities of close guanxi within organizations," Asia Pacific Journal of Management, vol. 26, no. 1, pp. 37-53, 2009.

[56] R. Nan and F. Ouyang, "Influence of social networks on citizens' willingness to participate in social governance: evidence from China," Complexity, vol. 2020, Article ID 3819514, 16 pages, 2020 . 